\title{
EI Estado frente al derecho de acceso a la vivienda digna ${ }^{1}$
}

\author{
Paula Beatriz Kohan ${ }^{2}$ Universidad de Buenos Aires, \\ Argentina
}

Revista Derechos en Acción ISSN 2525-1678/ e-ISSN 2525-1686

Año 4/Nº 13, Primavera 2019 (21 septiembre a 20 diciembre), 500-507

DOl: https://doi.org/10.24215/25251678e348

\section{Introducción}

El derecho a una vivienda digna se encuentra consagrado en nuestro ordenamiento jurídico interno. Así, el artículo 14 bis de la Constitución Nacional prevé que "El Estado otorgará los beneficios de la seguridad social, que tendrá carácter de integral e irrenunciable...", y que "... la ley establecerá [...] el acceso a una vivienda digna”. Asimismo, el artículo 75 inc. 22 eleva al rango de jerarquía constitucional a diversos instrumentos internacionales de Derechos Humanos, destacándose en materia de derecho a la vivienda la Convención Americana de Derechos Humanos (en adelante $\mathrm{CADH}$ ) y el Pacto Internacional de Derechos Económicos, Sociales y Culturales (en adelante PIDESC). A pesar de dicho reconocimiento, el derecho a una vivienda digna ha suscitado controversias sobre su contenido y alcances, así como sobre las obligaciones que conlleva para el Estado argentino. Estos puntos serán desarrollados a continuación.

\footnotetext{
1 Trabajo elaborado en el marco de la materia "Elementos de Derecho Constitucional", cátedra del Dr. Raúl Gustavo Ferreyra, a cargo del Dr. Mario Francisco Manuel Cámpora, Facultad de Derecho, Universidad de Buenos Aires.

2 Estudiante de la carrera de Abogacía en la Facultad de Derecho de la Universidad de Buenos Aires.
} 


\section{Contenido y alcances del derecho de acceso a una vivienda digna}

En la clasificación de los derechos humanos, el derecho a una vivienda digna forma parte de los derechos económicos, sociales y culturales. Si bien su distinción con los derechos civiles y políticos ha sido relativizada ${ }^{3}$, dicha categoría enfatiza la importancia que revisten para el desarrollo de una vida digna en el marco de una sociedad justa y la necesidad de que el Estado promueva las condiciones para su efectivo ejercicio a través de acciones positivas.

Además de la función social que se le reconoce a esta clase de derechos, es importante tener en cuenta el concepto de indivisibilidad e interdependencia de los derechos humanos para comprender el lugar que el derecho a la vivienda ocupa en nuestro ordenamiento jurídico. En este sentido, Corti señala que la asignación de derechos busca proteger bienes básicos como la autonomía personal, la vida digna y la autodeterminación política, permitiendo el desarrollo de un plan de vida propio en un contexto humanamente decente ${ }^{4}$. Por este motivo, los derechos reconocidos en la Constitución en general y el derecho a la vivienda digna en particular, deben entenderse de manera articulada e integral. Esta concepción resulta compleja, en la medida en que existen múltiples derechos reconocidos que deben ser alcanzados por el conjunto de la sociedad. Según el autor mencionado, deberá solucionarse en cada caso concreto las eventuales colisiones que pudieren presentarse entre ellos.

En esta línea se pronunció el Comité de Derechos Económicos, Sociales y Culturales (en adelante el Comité) ${ }^{5}$ cuando

3 Courtis, Christian. "Los derechos sociales como derechos", publicado en Abramovich, Víctor y Courtis, Christian (2011). "Apuntes sobre la exigibilidad judicial de los derechos sociales", disponible en: red.pucp.edu.pe/ridei/files/2011/08/110509.doc_.pdf.

4 Corti, Horacio (2012). "Derecho constitucional presupuestario", Abeledo Perrot.

5 ONU, Comité de Derechos Económicos, Sociales y Culturales, Observación General № 4 : El derecho a una vivienda adecuada, 1991. 
sostuvo que el derecho a una vivienda adecuada constituye uno de los elementos fundamentales para alcanzar un nivel de vida adecuado, definiéndolo como "el derecho a vivir en seguridad,

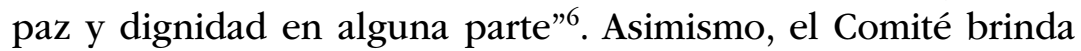
un conjunto de pautas sobre su contenido concreto. El derecho a la vivienda no debe entenderse con un sentido restrictivo, que implique sólo un techo, sino como el derecho a una vivienda "adecuada". La adecuación se alcanza cuando se cumplen los requisitos de seguridad jurídica de la tenencia; disponibilidad de servicios, materiales, facilidades e infraestructura; gastos soportables; habitabilidad; asequibilidad; lugar; y adecuación cultural. De conjunto, estos requisitos implican que una persona ejercerá su derecho de acceso a una vivienda adecuada cuando le permita desarrollar su vida de forma regular y gozando del resto de los derechos fundamentales: cuando se encuentre protegida legalmente frente a cualquier tipo de amenazas o posibilidad de desalojo; cuando se encuentre protegida materialmente en su integridad física frente a situaciones de inseguridad, las desavenencias del clima, etc.; cuando le permita acceder a los servicios sociales, de salud y educación; cuando le posibilite acceder a opciones de empleo; y cuando fácticamente logre acceder con sus recursos a la misma. En este punto, resulta relevante la mención que el Comité hace respecto a que deben atenderse las necesidades de los grupos más desfavorecidos.

\section{Obligaciones del Estado argentino respecto al derecho de acceso a una vivienda digna}

De manera general, el compromiso adoptado por el Estado frente al reconocimiento de los derechos humanos se encuentra explicitado en los artículos 1 y 2 de la $\mathrm{CADH}$, donde menciona la "obligación de respetar los derechos", “... garantizar su libre y pleno ejercicio..." , y el "deber de adoptar disposiciones de

6 Ibidem.

7 Sobre estas obligaciones genéricas, la Corte Interamericana de Derechos Humanos ha entendido "respetar" en términos de limitación al ejercicio de la función pública, es decir, 
derecho interno", y “... adoptar [...] las medidas legislativas o de otro carácter que fueren necesarias para hacer efectivos tales derechos y libertades". En este sentido, se requiere que los Estados intervengan activamente para facilitar el efectivo ejercicio y goce de los derechos.

En referencia a la categoría de los derechos económicos, sociales y culturales, y de acuerdo al artículo 26 de la $\mathrm{CADH}$, los Estados se comprometen a adoptar las providencias para "lograr progresivamente la plena efectividad [...], en la medida de los recursos disponibles, por vía legislativa $u$ otros medios apropiados" $"$. La índole de estas obligaciones ha sido explicitada por el Comité9. Reconoce obligaciones de conducta y de resultado, entendiendo que los Estados deben adoptar medidas positivas pero que sólo con ello no alcanza: deben cumplirse ciertos objetivos. Por eso, si bien contempla las limitaciones de recursos de los Estados, establece que deben cumplir con obligaciones de efecto inmediato, independientemente de que la CADH indique la ampliación progresiva y paulatina de estos derechos. En este grupo quedan comprendidas las obligaciones de garantizar la no discriminación en el ejercicio de los derechos; adoptar medidas deliberadas, concretas y orientadas claramente hacia su cumplimiento; y asegurar la satisfacción de

impone un deber de abstención a los Estados, de no generar obstáculos ni lesiones a los derechos y libertades reconocidos por la CADH. En cuanto a la obligación "garantizar su libre y pleno ejercicio", la Corte IDH sostuvo que los Estados deben "prevenir, investigar y sancionar toda violación de los derechos reconocidos", procurando, en la medida de lo posible, la reparación de los daños producidos. Ver Corte Interamericana de Derechos Humanos, "Velásquez Rodríguez vs. Honduras", 17 de agosto de 1990.

8 En esta línea, Corti ha señalado distintas etapas en el desarrollo de los derechos fundamentales, en las que tienen lugar diversas obligaciones por parte del Estado: la reglamentación de los derechos, el establecimiento de las estructuras organizativas requeridas para ponerlos en práctica, la ejecución de acciones públicas que los resguarden y la actuación de los órganos jurisdiccionales del Estado frente a eventuales lesiones de los derechos. Todas estas acciones por parte del Estado aseguran el ejercicio habitual de los derechos, y tanto por omitirse como por realizarse de manera inadecuada, el Estado puede incurrir en su violación.

9 ONU, Comité de Derechos Económicos, Sociales y Culturales, Observación General № 3 : La índole de las obligaciones de los Estados Partes, 1990. 
niveles esenciales de cada uno de ellos. Se aclara, asimismo, que las restricciones de recursos no eximen a los Estados de estas obligaciones, debiendo proteger a los miembros vulnerables de la sociedad.

Específicamente respecto al derecho a la vivienda, el Comité enfatiza este último punto, inclusive haciendo responsable al Estado por el deterioro de las condiciones de vida y de vivienda en tiempos de contracción económica. Además, considera que el abordaje respecto al derecho a la vivienda requiere la adopción de una estrategia nacional de vivienda sumamente detallada y la vigilancia eficaz de la situación con respecto a la vivienda. Ambas exigencias constituyen obligaciones de efecto inmediato $^{10}$.

Por último, con respecto a los alcances del derecho de acceso a la vivienda y su vinculación con los recursos del Estado que permiten su efectivización, Corti desarrolla una muy interesante graduación de los derechos, que resulta útil para zanjar el debate sobre su programaticidad u operatividad. Afirma que la Constitución establece un contenido mínimo y esencial de cada uno de los derechos con su sola enunciación, y que el nivel que de los mismos debe asegurarse es el que supone su ejercicio habitual, normal, típico o medio. Este grado de ejercicio medio puede restringirse a su contenido mínimo en momentos de emergencia, pero nunca suprimirse. Del mismo modo, las cláusulas de progresividad y de igualdad de oportunidades contempladas en el artículo 75 incs. 19 y 23 de la Constitución prevén el eventual ejercicio pleno de los derechos fundamentales, por encima de su nivel medio. De manera que la falta de recursos y/o las circunstancias de emergencia no dan lugar a los Estados para que omitan o suspendan el cumplimiento de sus obligaciones respecto a los derechos.

10 ONU, Comité de Derechos Económicos, Sociales y Culturales, Observación General № 4:

El derecho a una vivienda adecuada, 1991. 


\section{Interpretación del derecho de acceso a la vivienda digna en un fallo de la Corte Suprema de Justicia de la Nación}

En el fallo "Q.C., S.Y. c/ Gobierno de la Ciudad Autónoma de Buenos Aires s/amparo", de fecha 24 de abril de 2012, la Corte Suprema de Justicia de la Nación (en adelante CSJN) sienta precedente sobre el contenido y alcances del derecho a la vivienda digna, enfrentándose a las interpretaciones realizadas previamente por el Tribunal Superior de Justicia de la Ciudad Autónoma de Buenos Aires (en adelante TSJC).

En este caso, una mujer con un hijo menor discapacitado en situación de calle demanda al gobierno de la Ciudad Autónoma de Buenos Aires para exigirle los medios para superar esa realidad y acceder al efectivo ejercicio del derecho a la vivienda, entre otros derechos que entendía que estaban siendo violados. Frente a estos hechos, el TSJC falló a favor de la demandada y la CSJN lo hizo en contra.

En sus argumentos, el TSJC entendió que el contenido mínimo y esencial del derecho a una vivienda digna consistía en un estándar de "abrigo", satisfecho por la política de red de albergues y paradores estatales, y el otorgamiento de subsidios a familias en situación de calle. Por el contrario, la CSJN entendió que dichas políticas no atendían las necesidades mínimas de la demandante, como las de salud, privacidad, integridad física, dignidad, etc. Es decir, entendió el derecho a una vivienda digna desde la perspectiva de la indivisibilidad e interdependencia de los derechos humanos, en el sentido de que contribuyen a garantizar la salud y el desarrollo de las personas.

Respecto de las obligaciones del Estado, el TSJC consideró que sobre el derecho a la vivienda debe tenerse una visión colectiva y no de cada caso concreto. Dicho derecho no consiste en que el Estado proporcione una vivienda a cada persona que le falte, sino en fijar programas de acceso a la misma de acuerdo a los recursos disponibles, en una perspectiva que contemple la paulatina progresividad en su goce. 
Por su parte, la CSJN consideró tres características generales de los derechos económicos, sociales y culturales: son normas operativas y, por eso, exigibles; dicha operatividad es de carácter derivado, en la medida en que comporta obligaciones de hacer por parte del Estado; tal operatividad derivada está sujeta al control de razonabilidad del Poder Judicial, es decir, las múltiples formas en que el Estado puede cumplir con sus obligaciones deben adecuarse a los fines perseguidos.

Un punto de discusión importante entre ambos tribunales es el referido a los recursos destinados a garantizar el derecho a la vivienda y su consideración para determinar si el Estado cumplía o incumplía sus obligaciones. Mientras el TSJC consideró suficiente que el Estado destine recursos a la adopción de medidas que procuren garantizar los derechos reconocidos, evaluándolas partir de la mejora que producen respecto al conjunto general de la población e independientemente de la situación concreta de cada individuo, la CSJN consideró que la obligación del Estado no se satisface con una determinada inversión de recursos, ni siquiera cuando resulte sumamente cuantiosa, sino cuando su uso sea eficiente. Asimismo, expuso que la falta de recursos no excusaba al Estado para incumplir sus obligaciones, y que debía protegerse a los grupos más desfavorecidos y marginados de la sociedad.

\section{Consideraciones finales}

De los distintos argumentos y razonamientos esgrimidos por el Comité sobre las normas que consagran el derecho de acceso a una vivienda digna, se desprende que la acción de los distintos poderes del Estado debe tener como horizonte el criterio pro homine y los fines constitucionales. Y esto, en el marco de la complejidad del sistema de derechos humanos, que involucra diversas dimensiones: la consideración del conjunto de los derechos (que en situaciones concretas colisionan entre sí); a su vez, del conjunto de la población que pretende gozar de todos los derechos fundamentales reconocidos (siendo cada persona, 
a su vez, responsable por el efectivo ejercicio de los derechos del resto de las personas); y la disponibilidad de recursos de los Estados (que en múltiples circunstancias resultan insuficientes).

A la luz de esta interpretación ha resuelto la CSJN en el caso examinado. Por el contrario, en el entendimiento del TSJC primó una perspectiva restrictiva del derecho de acceso a una vivienda digna, independiente del conjunto de los derechos humanos, y aislando, en la evaluación de las medidas adoptadas por el Poder Ejecutivo para garantizarlo, los resultados obtenidos con ellas.

\section{Bibliografía}

Bidart Campos, Germán (2006). "Manual de la Constitución reformada", EDIAR.

Corte Interamericana de Derechos Humanos, "Velásquez Rodríguez vs. Honduras", 17 de agosto de 1990.

Corte Suprema de Justicia de la Nación "Q.C., S.Y. c/GCBA s/amparo", 24 de abril de 2012.

Corti, Horacio (2012). "Derecho constitucional presupuestario", Abeledo Perrot.

Courtis, Christian. "Los derechos sociales como derechos", publicado en Abramovich, Víctor y Courtis, Christian (2011). "Apuntes sobre la exigibilidad judicial de los derechos sociales", disponible en: red.pucp.edu.pe/ridei/files/2011/08/110509. doc_.pdf.

ONU, Comité de Derechos Económicos, Sociales y Culturales, Observación General $\mathrm{N}^{\mathrm{o}}$ 3: La índole de las obligaciones de los Estados Partes, 1990.

ONU, Comité de Derechos Económicos, Sociales y Culturales, Observación General $\mathrm{N}^{\circ}$ 4: El derecho a una vivienda adecuada, 1991.

Sabsay, Daniel. "El acceso a una vivienda digna en un fallo de la Corte SupremadeJusticiadela Nación”, publicadoenla revista"Pensaren derecho", disponible en: http://derecho.uba.ar/publicaciones/ pensar-en-derecho/revistas/0/el-acceso-a-la-vivienda-dignaen-un-fallo-de-la-corte-suprema-de-justicia-de-la-nacion.pdf. 